\title{
Analisis Bahaya dan Resiko Kerja di Industri Pengolahan Teh dengan Metode HIRA atau IBPR
}

\author{
Melisa Nurul Aini ${ }^{1}$, Arif Nuryono ${ }^{* 2}$ \\ Teknik Industri Fakultas Teknik, Universitas Bhayangkara Jakarta \\ e-mail: ${ }^{1}$ melisanurulaini48@ gmail.com, ${ }^{* 2}$ arif.nuryono@ dsn.ubharajaya.ac.id
}

\begin{abstract}
Occupational Health and Safety $(\mathrm{OHS})$ is an important aspect in the industry. The tea processing industry is one of the industries which has a high potential for accidents, a tea processing company in 2018 experienced 94 work accident cases, with $F R=5.04$. Pareto highest accident case is scratched, 34 cases. Therefore, it is necessary to study hazard identification and risk assessment in the tea processing, namely blending, filling and packing. The study was conducted using the HIRA (hazard identification \& Risk Assessment) approach. The HIRA method starts from hazard identification, assessing risks and controlling hazards / risks. From the results of observation and data analysis, the identified hazards are mechanical and chemical hazards in all processes. The second stage of risk assessment in the extreme category is being hit by a press, exposed to chemicals and slipping, and everything is in the filling process. After being controlled by the hazard control hierarchy, the risk of being hit by a press drops to low, while the risk of being exposed to chemicals decreases to high, and the risk of slipping decreases to low.
\end{abstract}

Keywords: Hazard, Risk, Hazard \& Risk Control .

\begin{abstract}
ABSTRAK
Kesehatan dan Keselamatan Kerja (K3) merupakan aspek yang penting dalam industri. Industri pengolahan teh termasuk industri yang punya potensi kecelakaan tinggi, sebuah perusahaan pengolahan teh tahun 2018 mengalami kecelakaan kerja 94 kasus, dengan $\mathrm{FR}=5,04$. Pareto kasus kecelakaan tertinggi adalah tergores, 34 kasus. Oleh sebab itu, perlu kajian identifikasi bahaya dan penilaian resiko di proses pengolahan teh, yaitu blending, filling dan packing. Kajian dilakukan dengan pendekatan metode HIRA (hazard identification \& Risk Assesment). Metode HIRA dimulai dari identifikasi bahaya, menilai resiko dan pengendalian bahaya/resiko. Dari hasil observasi dan analisis data, bahaya yang teridentifikasi adalah bahaya mekanis dan kimia di semua proses. Tahap kedua penilaian resiko dengan kategori extrim adalah terkena mesin press, terpapar bahan kimia dan terpeleset, dan semuanya di proses filling. Setelah dikendalikan dengan hirarki control bahaya, resiko terkena mesin press turun menjadi low, sedangkan resiko terpapar kimia turun menjadi high, dan resiko terpeleset turun menjadi low.
\end{abstract}

Kata Kunci: Bahaya, Resiko, Pengendalian bahaya \& resiko

\section{PENDAHULUAN}

Industri manufaktur merupakan industri yang mengolah bahan baku menjadi produk setengah jadi maupun produk jadi. Dalam proses produksi industri manufaktur memerlukan $\mathrm{K} 3$, aspek yang penting dalam perusahaan dan berkaitan erat dengan Kesehatan dan Keselamatan Kerja (K3). Perlindungan terhadap tenaga kerja merupakan suatu kewajiban yang harus diberikan oleh pihak perusahaan terhadap pegawainya, sehingga pegawai dapat bekerja lebih tenang, aman, nyaman dan target produksi dapat terpenuhi (Mangkunegara, 2016).

Kajian dan penelitian tentang K3 ini difokuskan pada industri pengolahan teh. Dimana industri ini memiliki aktivitas pertanian mulai dari perkebunan sampai pada 
pengolahannya, aktivitas yang melibatkan tenaga kerja, alat, metode, biaya, dan material serta waktu yang cukup besar. Industri ini memiliki kemungkinan bahaya dan resiko, bahkan kecelakaan kerja dalam aktifitasnya. Ada 3 aktifitas (proses) utama dari industri ini, yaitu blending, filling dan packing. Jika dilihat dari jenis pekerjaannya dimana banyak melibatkan tenaga manusia, kemungkinan bahaya dan paparannya lebih banyak mengganggu kesehatan manusia.

Pada tahun 2018, industri atau perusahaan ini sempat mengalami stop produksi karena no operator. Dan itu disebabkan karena naiknya tingkat kecelakaan kerja yang berdampak pada kesehatan pekerja. Berikut datanya :

\begin{tabular}{|c|c|c|c|c|c|}
\hline \multirow[b]{2}{*}{ Bulan } & \multicolumn{5}{|c|}{ Injury (Cedera) } \\
\hline & ISPA & $\begin{array}{l}\text { Flek } \\
\text { Paru- } \\
\text { Paru }\end{array}$ & Tergores & $\begin{array}{l}\text { Terkena } \\
\text { Mesin } \\
\text { Pres }\end{array}$ & $\begin{array}{c}\text { Paparan } \\
\text { Panas }\end{array}$ \\
\hline Januari & 1 & 0 & 2 & 0 & 1 \\
\hline Februari & 0 & 0 & 3 & 1 & 3 \\
\hline Maret & 1 & 0 & 3 & 2 & 3 \\
\hline April & 0 & 2 & 1 & 0 & 0 \\
\hline Mei & 1 & 1 & 3 & 1 & 1 \\
\hline Juni & 0 & 2 & 2 & 2 & 3 \\
\hline Juli & 3 & 0 & 4 & 0 & 3 \\
\hline Agustus & 0 & 3 & 2 & 3 & 1 \\
\hline September & 2 & 2 & 3 & 0 & 3 \\
\hline Oktober & 0 & 0 & 4 & 0 & 4 \\
\hline November & 4 & 2 & 4 & 0 & 1 \\
\hline Desember & 0 & 0 & 3 & 0 & 4 \\
\hline Jumlah & 12 & 12 & 34 & 9 & 27 \\
\hline
\end{tabular}

(Sumber: Pengumpulan Data, 2018)

Dari data kecelakaan injury (cidera) ada 94 kasus, dalam satu tahun. Ini termasuk fenomena yang luar biasa. Dan dengan jumlah karyawan 10.000 dengan jam kerja 7 jam perhari atau 3 shift, sehingga frekuensi rate dan severity rate nya adalah :

$\mathrm{Fr}=\frac{\text { Jumlah kecelakaan }}{\text { Total Jumlah jam kerja }} \times 1.000 .000$

$\mathrm{Fr}=5,06$

Artinya dalam 1.000.000 jam kerja karyawan terjadi 5 kali kasus kecelakaan.

Jika di Pareto-kan problem yang paling besar adalah :

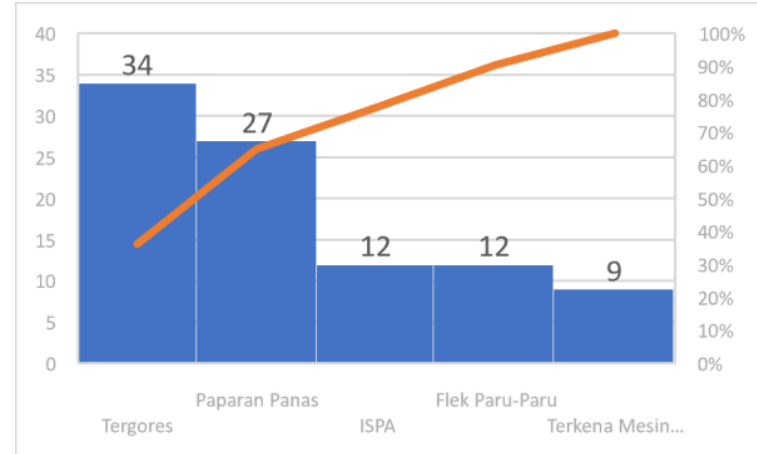

(Sumber: Pengolahan Data, 2018) Gambar 1. Diagram Pareto

Berdasarkan data diatas bahaya dan resiko tergores termasuk yang paling besar potensi kecelakaannya. Oleh sebab itu, dalam kajian ini peneliti mencoba untuk mengidentifikasi bahaya dan menilai resiko pada proses blending, filling dan packing industri pengolahan teh, dengan pendekatan metode HIRA atau IBPR.

\subsection{KESELAMATAN \& KESEHATAN KERJA}

Istilah keselamatan mencakup kedua istilah resiko keselamatan dan resiko kesehatan. Keselamatan kerja menunjukkan kondisi yang aman atau selamat dari penderitaan, kerusakan atau kerugian di tempat kerja. (Mangkunegara,2016). Aspekaspek dari resiko keselamatan adalah lingkungan kerja yang dapat menyebabkan kebakaran, ketakutan aliran listrik, terpotong, luka memar, keseleo, patah tulang, kerugian alat tubuh, penglihatan dan pendengaran. Aspek-aspek tersebut dihubungkan dengan perlengkapan perusahaan atau lingkungan fisik dan mencakup tugas-tugas kerja yang membutuhkan pemeliharaan dan latihan, sedangkan kesehatan kerja menunjukkan kondisi yang bebas dari gangguan fisik, mental, emosi atau rasa sakit yang disebabkan oleh lingkungan kerja. Faktor-faktor dalam lingkungan kerja yang bekerja melebihi periode waktu yang ditentukan, lingkungan yang dapat membuat stres emosi atau gangguan fisik merupakan resiko kesehatan.

Menurut Rivai (2006), tujuan dan pentingnya keselamatan kerja meliputi:

- Menurunnya jumlah hari kerja yang hilang agar meningkatnya produktivitas. 
- Meningkatnya efisiensi dan juga kualitas para pekerja yang lebih berkomitmen.

- Menurunkan semua biaya-biaya kesehatan dan juga asuransi.

- Tingkat kompensasi pekerja dan pembayaran langsung yang lebih rendah karena menurunnya pengajuan klaim.

- Fleksibilitas dan adaptabilitas yang lebih besar sebagai akibat dari meningkatnya partisipasi dan rasa kepemilikan.

- Rasio seleksi tenaga kerja yang lebih baik karena meningkatnya citra perusahaan.

\subsection{Kecelakaan Kerja}

Menurut Notoatmodjo (2003), kecelakaan kerja disebabkan oleh 2 faktor utama yakni faktor fisik dan faktor manusia. Oleh sebab itu, kecelakaan kerja juga merupakan bagian dari kesehatan kerja. Kecelakaan kerja merupakan kejadian yang tidak terduga dan tidak diharapkan akibat dari kerja.

Faktor-faktor penyebab kecelakaan kerja menurut Henrich (1980) yang dikutip oleh Hamzah (2005), tindakan tidak aman (unsafe action), kondisi tidak aman (unsafe condition) dan faktor nasib atau kejadian yang tidak bisa diramalkan (unsafe of god) merupakan penyebab-penyebab dasar dari terjadinya kecelakaan kerja.

Tindakan tidak aman (unsafe action) meliputi:

1. Tidak taat peraturan,

2. Bekerja tanpa kewenangan,

3. Tidak memakai APD, dan

4. Tidak aman dalam mengangkat, menarik atau mendorong.

Kondisi tidak aman (unsafe condition) terdiri atas:

1. Layout pekerjaan,

2. Penggunaan peralatan,

3. Kebisingan, dan

4. Kondisi atmosfir kerja.

\subsection{Bahaya dan Resiko}

\section{Bahaya (Hazard)}

- Anything that cause harm; Cehmical, heat, noise, moving machine part. (HSE-UK)
- A condition or practice with the potensial for harm. (British Standard Institute; 2007)

Di dalam bahasa Indonesia dapat didefinisikan bahwa "Bahaya adalah segala sesuatu yang berpotensi untuk menyebabkan kerugian (cidera pada manusia, kerusakan pada alat/proses/lingkungan sekitar).

2. Resiko (Risk)

- The chance, geat or small, that someone may be harmed by a hazard. (HSE-UK)

- Change of loss; A measure of the probability and potensial severity of harm. (British Standard Institute; 2007)

Di dalam bahasa Indonesia dapat didefinisikan bahwa "Risiko adalah kemungkinan mendapatkan kerugian (cidera pada manusia, kerusakan pada alat/proses /lingkungan sekitar) dari suatu bahaya".

3. Bahaya-bahaya yang Ada di Tempat Kerja

Proses terjadinya kecelakaan diawali dengan adanya bahaya. Oleh karena itu, seorang Pengawas Operasional harus memahami bahaya-bahaya yang ada di tempat kerja.

Tipe-tipe bahaya yang ada di tempat kerja antara lain ( Ramesh, R, . 2017)

1. Bahan Kimia

Bahaya kimia umumnya berasal dari bahan-bahan kimia yang ada di tempat kerja. Bahaya kimia dapat mempengaruhi atau masuk ke dalam tubuh pekerja melalui pernafasan, pencernaan, kontak kulit, atau tertusuk/tersuntik. Contoh bahaya kimia antara lain: Debu, Asap (smog), Gas, Uap, Fume, Kabut (mists/aerosol), Bedak/ Tepung (vapors), dan Fiber.

2. Bahaya Fisik

Bahaya fisik biasanya berasal dari faktor fisika, seperti kebisingan, getaran, pencahayaan, radiasi, temperatur, dan tekanan. 
3. Bahaya Biologi

Bahaya yang timbul oleh suatu mahkluk hidup baik tampak (makro biologi) maupun tidak tampak (mikro biologi) oleh mata. Contoh bahaya mikro biologi adalah bakteri, virus, jamur (fungi), tengu (mites); dan contoh bahaya makro biologi adalah serangga, parasit, tumbuhan, dan binatang.

4. Bahaya Ergonomi

Bahaya ergonomi adalah bahaya yang terjadi akibat ketidaksesuaian antara seseorang/pekerja dengan peralatan atau lingkungan tempat kerjanya. Contoh bahaya ergonomi adalah:

- Stress Fisik (Physical Stresses); ruang sempit \& terbatas, manarik, mendorong, canggung/ aneh (awkward) or static postures, pekerjaan terlalu keras (overexertion), repetitive motion, fatigue, excessive force, and direct pressure

- Stress kejiwaan/ mental (Psychological Stresses); bosan (monotony), terlalu berat (overload), perceptual confusion.

5. Bahaya Mekanis

Bahaya yang berasal dari faktor mekanis dalam permesinan atau peralatan, seperti bahaya yang ada pada titik operasi pemotongan, pemboran; bahaya pada titik jepit (nip point) seperti putaran pulley, roller; bahaya pada gerakan mesin yang maju mundur atau naik turun, dan bahaya pada tempat pemindahan dan pada bagian yang berputar atau bergerak lainnya dari suatu peralatan atau permesinan.

6. Bahaya Lingkungan Sekitar

Bahaya yang muncul dari karakteristik lingkungan kerja seperti kemiringan, permukaan tidak rata atau licin, dan cuaca buruk.

7. Bahaya Psikososial

Bahaya yang mempengaruhi psikologi pekerja akibat interaksi sosial pekerja seperti intimidasi, trauma, pola gilir kerja, pola promosi, dan pengorganisasian kerja.

8. Bahaya Tingkah Laku
Bahaya dari faktor prilaku pekerja seperti ketidak patuhan, kurang keahlian, tugas baru/ tidak rutin, overconfident, sok jago/ pintar, tidak peduli/ masa bodo.

9. Bahaya Kelistrikkan

Bahaya yang timbul akibat instalasi atau peralatan listrik, seperti pemasangan kabel, penyambungan tahanan pembumian (grounding system), panel listrik, dan saklar.

\subsection{Identifikasi Bahaya}

Metode indentifikasi bahaya :

1. Observasi atau Inspeksi Terencana

Observasi/pengamatan terhadap kondisi fakta tempat kerja, peralatan dan sebagainya atau inspeksi terencana yang lebih focus terhadap bahaya tertentu, dengan menggunakan lembar pemeriksaan (Checklist) dan Indeks. Biasanya digunakan untuk identifikasi bahaya yang sudah ada aktivitas kerjanya.

2. Brainstorming

Untuk proses yang belum dilakukan atau berdasarkan pertimbangan seperti jarak yang jauh sehingga sulit dilakukan observasi atau inspeksi, maka identifikasi bahaya dapat dilakukan melalui brainstorming. Terdapat beberapa teknik dalam mengidentifikasi bahaya, diantaranya Job Safety Analysys, What-if Analysis, Hazard and Operability Studies (Hazop). Fault Tree Analysis (FTA), dan Failure Mode and Effect Analysis (FMEA) dan HIRA, namun demikian dalam penelitian ini kita peneliti fokus pada HIRA.

\section{A. Penilaian Resiko}

Penilaian risiko adalah proses mengakaji apakah risiko yang ada dapat diterima atau tidak oleh pekerja. Penilaian resiko sebaiknya dilakukan dengan melibatkan beberapa orang (berkelompok) seperti pekerja yang bekerja secara langsung, pengawas, petugas pengelola keselamatan, dan orang-orang lain yang terkait karena keahlian atau pekerjaan terhadap risiko yang akan dikaji. Penilaian risiko dapat 
dilakukan secara kualitatif, semi kuantitatif, maupun kuantitatif.

Peneliti dalam mengidentifikasi dan menilai resiko, menggunakan metode kuantitif untuk menilai resiko.

Tabel 1. Penilaian Resiko

\begin{tabular}{|c|c|c|c|c|c|c|}
\hline & \multicolumn{5}{|c|}{ Impact } \\
\hline & & Trivial & Minor & Moderate & Major & Extreme \\
\hline \multirow{5}{*}{ 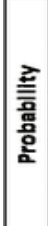 } & Rare & Low & Low & Low & Medium & Medium \\
\hline & Unlikely & Low & Low & Medium & Medium & Medium \\
\hline & Moderate & Low & Medium & Medium & Medium & High \\
\hline & Likely & Medium & Medium & Medium & High & High \\
\hline & Very likely & Medium & Medium & High & High & High \\
\hline
\end{tabular}

(Sumber : EHS-MU-AST, 2019)

\section{B. Pengendalian bahaya dan resiko}

Setelah bahaya-bahaya yang ada diidentifikasi dan telah dinilai risikonya maka selanjutnya dikendalikan agar dapat bekerja secara aman. Dalam menentukan langkahlangkah pengendalian maka konsep yang harus dipahami adalah hirarki pengendalian (Hierarchi Controls) sehingga pengendalian yang dilakukan berlangsung efektif. (Markkanen, P. K.,2004).

Hierarcy pengendalian berarti tahapan pengendalian yang harus dipertimbangkan secara berurutan, dari pengendalian pertama yang merupakan pengendalian paling efektif, ke pengendalian ke dua yang berkurang efektifitasnya, sampai pengendalian yang terakahir yang paling tidak efektif.

Hierarcy pengendalian yang banyak dijumpai dalam buku-buku keselamatan dan kesehatan kerja adalah sebagai berikut:

1. Eliminasi

2. Substitusi

3. Engineering Control

4. Administratif Control

5. Alat Pelindung Diri

Ada juga yang menyatakan hierarcy pengendalian bahaya terdiri atas:

1. Elimination

2. Substitution

3. Engineering/Redesigning

4. Isolation

5. Monitoring

6. Administrative

7. Education \& Training

8. Work Practice

9. Maintenance

\section{Alat Pelindung Diri}

\section{METODE PENELITIAN}

Jenis penelitian yang digunakan dalam penelitian ini adalah jenis penelitian deskriptif. Penelitian deskriptif merupakan penelitian yang menggambarkan sejumlah data yang kemudian dianalisis dan dibandingkan berdasarkan kenyataan yang sedang berlangsung selanjutnya mencoba untuk memberikan pemecahan masalah yang ada supaya memperoleh hasil yang lebih baik dari sebelumnya.

\subsection{Jenis Data}

Dalam penelitian ini jenis data yang digunakan adalah :

- Data primer : data dari observasi dan wawancara

- Data sekunder : data jurnal, buku dan referensi lain bersifat teoritis.

\subsection{Metode Penelitian}

Metode yang akan dilakukan dalam penelitian ini adalah :

- Observasi : meliputi data kecelakaan kerja, penyebab kecelakaan, jenis bahaya

- Studi pustaka : pendekatan teknis dan teoritis mengenai $\mathrm{K} 3 \mathrm{LH}$

\subsection{Pengolahan Data}

Pengolahan data penelitan ini ada dua jenis yaitu:

1. Berdasarkan data history (data sebelumnya) yang diperoleh dari perusahaan perlu di plot dalam perhitungan Microsoft Excel. Data kecelakaan kerja yang ada dibuat dalam bentuk grafik agar dapat melihat pola data tersebut dan dapat menentukan data tersebut menyerupai pola siklis, musiman, horizontal, tren.

2. Melakukan plot pada data history kecelakaan kerja agar dapat mengurangi tingkat kecelakaan kerja sesuai dengan permintaan perusahaan. 


\subsection{Metode HIRA}

Identifikasi potensi bahaya merupakan suatu proses yang dilakukan untuk mengenali seluruh situasi atau kejadian yang berpotensi sebagai penyebab kecelakaan kerja dan penyakit akibat kerja yang mungkin timbul ditempat kerja, sehingga segera dilakukan tindakan pencegahan dan pengendalian agar tidak mengakibatkan kerugian terhadap perusahaan maupun tenaga kerja. (Santoso, G, 2004) Sedangkan Penilaian risiko merupakan proses mengevaluasi tinggi rendahnya tingkat risiko yang timbul dengan memperhitungkan hasil estimasi tingkat kekerapan dan tingkat keparahan, sehingga nantinya diklasifikasikan kedalam tingkat risiko tidak ada bahaya, bahaya rendah, bahaya sedang, bahaya serius, atau bahaya sangat tinggi.

\section{HASIL DAN PEMBAHASAN}

\subsection{Identifikasi Proses Pengolahan Teh}

Daftar identifikasi potensi bahaya yang ada pada proses pengolahan teh dapat dilihat pada tabel berikut :

Tabel 2. Identifikasi Bahaya Blending

\begin{tabular}{|c|c|c|c|c|c|c|c|c|}
\hline $\begin{array}{c}\text { Daftar Operasional } \\
\text { dan Proses }\end{array}$ & \multicolumn{2}{|r|}{ Rimcian Aktivitas } & SituasiKondisi & $\begin{array}{r}\text { Kesehatan } \\
\text { Keselamatan } \\
\text { /Lingkungan }\end{array}$ & $\begin{array}{c}\text { Rincian Bahaya } \\
\text { dan Aspek } \\
\text { Lingkungan }\end{array}$ & $\begin{array}{c}\text { Jenis } \\
\text { /Aspek } \\
\text { Bahaya }\end{array}$ & $\begin{array}{c}\text { Rincian Potensi } \\
\text { Resiko dan } \\
\text { Dampak }\end{array}$ & $\begin{array}{c}\text { Analisa Konsekuen } \\
\text { Maksimum }\end{array}$ \\
\hline \multirow{5}{*}{ Filling } & 1 & $\begin{array}{l}\text { Memasukkan cup ke } \\
\text { dalampengisian cup }\end{array}$ & R & Keselammatan & \begin{tabular}{|l|} 
Tergores pisau \\
pemisah cup
\end{tabular} & Mekanis & Luka Gores & \begin{tabular}{|l} 
Infeksi Luka \\
(Cedera)
\end{tabular} \\
\hline & 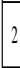 & $\begin{array}{l}\text { Pengaambilan sample } \\
\text { untuk QC }\end{array}$ & $\mathrm{R}$ & Keselammetan & \begin{tabular}{|l|} 
Terkeram mesin \\
press
\end{tabular} & Mekanis & Luka Bakar & Luka Bakar \\
\hline & \multirow{3}{*}{\multicolumn{2}{|c|}{$\begin{array}{l}\text { Ketika Sedang } \\
\text { Cleaning In Place }\end{array}$}} & $\mathrm{R}$ & Keselammatan & Terpapar panas & Kimia & Luka Melepuh & Luka Melepuh \\
\hline & & & $\mathrm{R}$ & Keselammetan & \begin{tabular}{|l|} 
Terpeleset hantai \\
basah
\end{tabular} & Mekanis & Terjatuh & $\begin{array}{l}\text { Cedera, bakkan } \\
\text { sampaik kematian }\end{array}$ \\
\hline & & & $\mathbb{R}$ & Kesehatan & $\begin{array}{l}\text { Terthirup bahan } \\
\text { kimia bertahayava }\end{array}$ & Kimia & Penyakit Paru-Paru & $\begin{array}{l}\text { Keracuman, bahkan } \\
\text { sampai kematian }\end{array}$ \\
\hline
\end{tabular}

(Sumber: Pengolahan Data, 2018)
Tabel 3. Identifikasi Bahaya Filling

\begin{tabular}{|c|c|c|c|c|c|c|c|c|}
\hline $\begin{array}{c}\text { Daftar Operasional } \\
\text { dan Proses }\end{array}$ & \multicolumn{2}{|r|}{ Rincian Aktivitas } & \begin{tabular}{|l|} 
SituasiKondisi \\
(RNR;N/AN:E) \\
\end{tabular} & $\begin{array}{c}\text { Kesehatan } \\
\text { Keselamatan } \\
\text { /Lingkungan } \\
\end{array}$ & $\begin{array}{c}\text { Rincian Bahaya } \\
\text { dan Aspek } \\
\text { Lingkungan }\end{array}$ & \begin{tabular}{|c|} 
Jenis \\
IAspek \\
Bahaya
\end{tabular} & $\begin{array}{c}\text { Rincian Potensi } \\
\text { Resiko dan } \\
\text { Dampak }\end{array}$ & $\begin{array}{c}\text { Analisa Konsekuensi } \\
\text { Maksimum }\end{array}$ \\
\hline \multirow{5}{*}{ Filling } & & $\begin{array}{l}\text { Memasulkkan cup ke } \\
\text { dalampengsianc cup }\end{array}$ & R & Keselamatan & $\begin{array}{l}\text { Tergores pisau } \\
\text { pemixah cup }\end{array}$ & Mekanis & Luka Gores & $\begin{array}{l}\text { Infeksi Luka } \\
\text { (Cedera) } \\
\end{array}$ \\
\hline & 2 & $\begin{array}{l}\text { Pengamblan sample } \\
\text { untuk } Q C\end{array}$ & R & Keselamatan & $\begin{array}{l}\text { Terkena mesin } \\
\text { press }\end{array}$ & Mekanis & Luka Bakar & Luka Bakar \\
\hline & \multirow{3}{*}{\multicolumn{2}{|c|}{$3 \begin{array}{l}\text { Ketika Sedang } \\
\text { Cleaning In Place }\end{array}$}} & $\mathrm{R}$ & Keselamatan & Terpapar panas & Kimia & Luka Melepuh & Luka Melpuh \\
\hline & & & $\mathrm{R}$ & Keselamatan & $\begin{array}{l}\text { Terpeleset lantai } \\
\text { basah }\end{array}$ & Mekanis & Terjatuh & $\begin{array}{l}\text { Cedera, bahkan } \\
\text { sampaik Kematian }\end{array}$ \\
\hline & & & $\mathbb{R}$ & Kesehatan & $\begin{array}{l}\text { Terthirup bahan } \\
\text { kimia bertahayaa }\end{array}$ & Kimia & PenyaktiParu-Paru & $\begin{array}{l}\text { Keracunan, bahkan } \\
\text { sampaik kematian }\end{array}$ \\
\hline
\end{tabular}

(Sumber: Pengolahan Data, 2018)

Tabel 4. Identifikasi Bahaya Packing

\begin{tabular}{|c|c|c|c|c|c|c|c|}
\hline $\begin{array}{c}\text { Daftar Operasional } \\
\text { dan Proses }\end{array}$ & \begin{tabular}{l|l} 
No. & Rincian Aktivitas
\end{tabular} & \begin{tabular}{|l|} 
SituasiKondisi \\
RNP.VIAN.EE)
\end{tabular} & $\begin{array}{l}\text { Kesehatan } \\
\text { Keselamatan } \\
\text { Kingkungan }\end{array}$ & $\begin{array}{l}\text { Rincian Bahaya } \\
\text { dan Aspek } \\
\text { Lingkungan }\end{array}$ & $\begin{array}{l}\text { Jenis } \\
\text { /Aspek } \\
\text { Bahaya }\end{array}$ & $\begin{array}{c}\text { Rincian Potensi } \\
\text { Resiko dan } \\
\text { Dampak }\end{array}$ & $\begin{array}{c}\text { Analisa Konsekuens } \\
\text { Maksimum }\end{array}$ \\
\hline & \begin{tabular}{l|l}
1 & Packing \\
\end{tabular} & $\mathrm{R}$ & Keselematan & Terpapar panas & Kimia & Luka Melepuh & Luka Melpuh \\
\hline Packing & \begin{tabular}{|l|l}
2 & Keitka Sedang \\
Cleaning In Place
\end{tabular} & NR & Keselematan & $\begin{array}{l}\text { Terpapar percikan } \\
\text { panas dan uap } \\
\text { panas }\end{array}$ & Kimia & Luka Melepuh & Luka Melpun \\
\hline
\end{tabular}

(Sumber: Pengolahan Data, 2018)

\subsection{Penilaian Resiko}

Tahap selanjutnya setelah mengidentifikasi kegiatan yang berpotensi bahaya maka dilanjutkan dengan menilai tingkat resiko dari potensi tersebut.

Tabel 5. Penilaian Resiko

\begin{tabular}{|c|l|c|c|c|}
\hline \multirow{2}{*}{ No. } & \multicolumn{1}{|c|}{ Resiko } & \multicolumn{2}{|c|}{ Analisis Resiko } & Tingkat \\
\cline { 3 - 5 } 1 & $\begin{array}{l}\text { Tergores } \\
\text { bagian } \\
\text { tajam }\end{array}$ & 3 & 2 & $\mathrm{M}$ \\
\hline 2 & $\begin{array}{l}\text { Terpapar } \\
\text { panas }\end{array}$ & 2 & 3 & $\mathrm{M}$ \\
\hline 3 & $\begin{array}{l}\text { Terpapar } \\
\text { panas }\end{array}$ & 2 & 3 & $\mathrm{M}$ \\
\hline 4 & $\begin{array}{l}\text { Terpapar } \\
\text { panas }\end{array}$ & 2 & 3 & $\mathrm{M}$ \\
\hline 5 & $\begin{array}{l}\text { Terpapar } \\
\text { percikan } \\
\text { panas dan } \\
\text { uap panas }\end{array}$ & 3 & 3 & $\mathrm{H}$ \\
\hline 6 & $\begin{array}{l}\text { Terpapar } \\
\text { air panas }\end{array}$ & 3 & 3 & $\mathrm{H}$ \\
\hline 7 & $\begin{array}{l}\text { Tergores } \\
\text { pisau }\end{array}$ & 3 & 3 & $\mathrm{H}$ \\
\hline
\end{tabular}




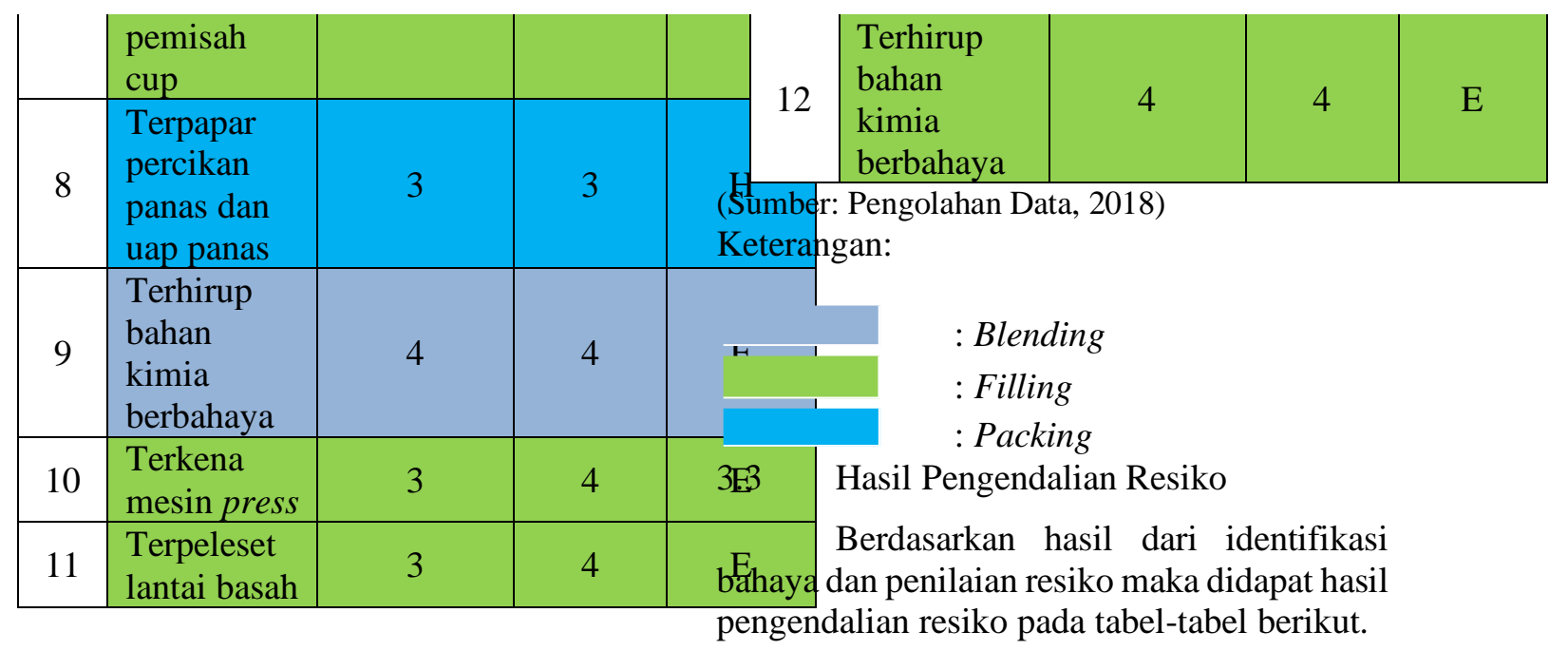

Tabel 6. Pengendalian Resiko Blending

\begin{tabular}{|c|c|c|c|c|}
\hline No & Resiko & $\begin{array}{l}\text { Tingkat } \\
\text { Resiko }\end{array}$ & & Pengendalian Resiko \\
\hline \multirow[t]{2}{*}{1} & \multirow{2}{*}{$\begin{array}{l}\text { Terhirup bahan } \\
\text { kimia } \\
\text { berbahaya }\end{array}$} & \multirow[t]{2}{*}{ E } & Administratif & $\begin{array}{l}\text { Pekerja harus selalu fokus saat } \\
\text { kontak langsung dengan bahan } \\
\text { kimia, menukar APD apabila } \\
\text { sudah tidak layak pakai }\end{array}$ \\
\hline & & & APD & $\begin{array}{l}\text { Menggunakan APD sesuai SOP } \\
\text { yang berlaku, seperti masker }\end{array}$ \\
\hline \multirow{3}{*}{2} & \multirow{3}{*}{$\begin{array}{l}\text { Tergores } \\
\text { bagian tajam }\end{array}$} & \multirow{3}{*}{$\mathbf{M}$} & Subtitusi & Mengganti cutter dengan gunting \\
\hline & & & Administratif & $\begin{array}{l}\text { Pekerja harus selalu berhati-hati } \\
\text { dalam membukka bahan baku }\end{array}$ \\
\hline & & & APD & $\begin{array}{l}\text { Menggunakan APD sarung tangan } \\
\text { karet }\end{array}$ \\
\hline \multirow[t]{2}{*}{3} & $\begin{array}{l}\text { Terpapar } \\
\text { percikan panas } \\
\text { dan uap panas }\end{array}$ & $\mathbf{H}$ & Administratif & $\begin{array}{l}\text { Berhati-hati dalam menuang bahan } \\
\text { dengan perlahan agar tidak terkena } \\
\text { percikan air panas yang ada di } \\
\text { dalam blending }\end{array}$ \\
\hline & & & APD & Menggunakan sarung tangan karet \\
\hline No. & Resiko & $\begin{array}{l}\text { Tingkat } \\
\text { Resiko }\end{array}$ & \multicolumn{2}{|r|}{ Pengendalian Resiko } \\
\hline & \multirow[t]{2}{*}{4 Terpapar panas } & \multirow[t]{2}{*}{$\mathbf{M}$} & Administratif & $\begin{array}{l}\text { Pekerja harus selalu fokus saat } \\
\text { kontak langsung dengan bahan } \\
\text { atau alat yang panas }\end{array}$ \\
\hline & & & APD & Menggunakan sarung tangan karet \\
\hline \multirow[t]{2}{*}{5} & \multirow[t]{2}{*}{$\begin{array}{l}\text { Terpapar air } \\
\text { panas }\end{array}$} & \multirow[t]{2}{*}{$\mathbf{H}$} & Administratif & $\begin{array}{l}\text { Pekerja harus selalu fokus saat } \\
\text { kontak langsung dengan bahan } \\
\text { atau alat yang panas }\end{array}$ \\
\hline & & & APD & Menggunakan sarung tangan karet \\
\hline
\end{tabular}

(Sumber: Pengolahan Data, 2018)

Tabel 7. Pengendalian Resiko Filling

\begin{tabular}{|c|c|c|c|c|}
\hline No. & Resilko & Tingkat Resiko & & Pengendalian Resiko \\
\hline \multirow{2}{*}{1} & \multirow{2}{*}{$\begin{array}{l}\text { Tergores pisau } \\
\text { pemisah cup }\end{array}$} & \multirow{2}{*}{ H } & Engineering & $\begin{array}{l}\text { Memberhentikan mesin ketika cupp } \\
\text { tersanghut di garpu pemisah cupp }\end{array}$ \\
\hline & & & Administratif & Berhati-bati dalam mengoperasikan mesin \\
\hline \multirow[b]{2}{*}{2} & \multirow[b]{2}{*}{$\begin{array}{l}\text { Terkena mesi } \\
\text { press }\end{array}$} & \multirow[b]{2}{*}{ E } & Fngineering & $\begin{array}{l}\text { Memberhentikan mesin ketika cup } \\
\text { tersanghut di mesia press }\end{array}$ \\
\hline & & & Administratif & $\begin{array}{l}\text { Pelerja harus memperhatikan pergerakkan } \\
\text { mesin dan menjaublan tubuh dari mesin } \\
\text { saat beroperasi }\end{array}$ \\
\hline $\mathrm{Ne}$ & Resiko & Tingkat Resiko & & Pengendalian Resiko \\
\hline \multirow[t]{2}{*}{3} & \multirow[t]{2}{*}{ Terpapar panas } & \multirow[t]{2}{*}{ M } & Administratif & $\begin{array}{l}\text { Pekerja harus se ha ha folves saat hoedak } \\
\text { langsung dengan bahan atau alat yang } \\
\text { panas }\end{array}$ \\
\hline & & & APD & Menggunakan sarung tangan karet \\
\hline \multirow{2}{*}{4} & \multirow{2}{*}{$\begin{array}{l}\text { Terpeleset lantai } \\
\text { basah }\end{array}$} & \multirow{2}{*}{ E } & Administratif & Pekerja harus sela ha folvus saat sedang CIP \\
\hline & & & $\mathrm{APD}$ & Menggunakan sepatu booss \\
\hline \multirow[t]{2}{*}{5} & \multirow{2}{*}{$\begin{array}{l}\text { Terhirup bahan } \\
\text { kimia bertahaya }\end{array}$} & \multirow[t]{2}{*}{ E } & Administratif & 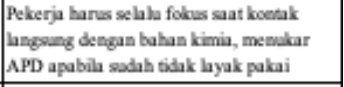 \\
\hline & & & $A P D$ & $\begin{array}{l}\text { Mengzunakan APD sesaai SOP yang } \\
\text { berlaku, seperti master }\end{array}$ \\
\hline
\end{tabular}

(Sumber: Pengolahan Data, 2018)

Tabel 8. Pengendalian Resiko Packing 


\begin{tabular}{|c|c|c|c|c|}
\hline No. & Resiko & $\begin{array}{l}\text { Tingkat } \\
\text { Resiko }\end{array}$ & & Pengendalian Resiko \\
\hline \multirow[t]{2}{*}{1} & \multirow[t]{2}{*}{ Terpapar pan } & \multirow[t]{2}{*}{$\mathrm{M}$} & Administratif & $\begin{array}{l}\text { Pekerja harus selalu fokus saat } \\
\text { kontak langsung dengan bahan atau } \\
\text { alat yang panas }\end{array}$ \\
\hline & & & APD & Menggunakan sarung tangan karet \\
\hline No. & Resiko & $\begin{array}{l}\text { Tingkat } \\
\text { Resiko } \\
\end{array}$ & & Pengendalian Resiko \\
\hline \multirow[t]{2}{*}{2} & $\begin{array}{l}\text { Terpapar } \\
\text { percikan } \\
\text { panas dan }\end{array}$ & \multirow[t]{2}{*}{$\mathrm{H}$} & Administratif & $\begin{array}{l}\text { Berhati-hati dalam menuang bahan } \\
\text { dengan perlahan }\end{array}$ \\
\hline & uap panas & & APD & Menggunakan sarung tangan karet \\
\hline
\end{tabular}

(Sumber: Pengolahan Data, 2018)

\subsection{Hasil Nilai Resiko setelah Pengendalian}

Berdasarkan hasil pengendalian resiko maka didapat hasil penilaian resiko setelah pengendalian resiko pada tabel-tabel berikut.

Tabel 9 Nilai Resiko Blending Pengendalian

\begin{tabular}{|c|c|c|c|c|c|}
\hline \multirow{1}{*}{} & No. & Resiko & \multicolumn{2}{|c|}{ Analisis Resiko } & \multirow{2}{*}{$\begin{array}{c}\text { Tingkat } \\
\text { Resiko }\end{array}$} \\
\cline { 2 - 5 } & 1 & $\begin{array}{l}\text { Terhirup } \\
\text { bahan kimia } \\
\text { berbahaya }\end{array}$ & 4 & 2 & $\mathrm{H}$ \\
\cline { 2 - 5 } Blending & 2 & $\begin{array}{l}\text { Tergores } \\
\text { bagian tajam }\end{array}$ & 2 & 2 & $\mathrm{~L}$ \\
\cline { 2 - 5 } & 3 & $\begin{array}{l}\text { Terpapar } \\
\text { percikan } \\
\text { panas dan } \\
\text { uap panas }\end{array}$ & 3 & 2 & $\mathrm{M}$ \\
\hline & 4 & Terpapar pan & 2 & 2 & $\mathrm{~L}$ \\
\hline & 5 & $\begin{array}{l}\text { Terpapar air } \\
\text { panas }\end{array}$ & 2 & 2 & $\mathrm{~L}$ \\
\hline
\end{tabular}

(Sumber: Pengolahan Data, 2018)

Tabel 10 Nilai Resiko Filling Pengendalian

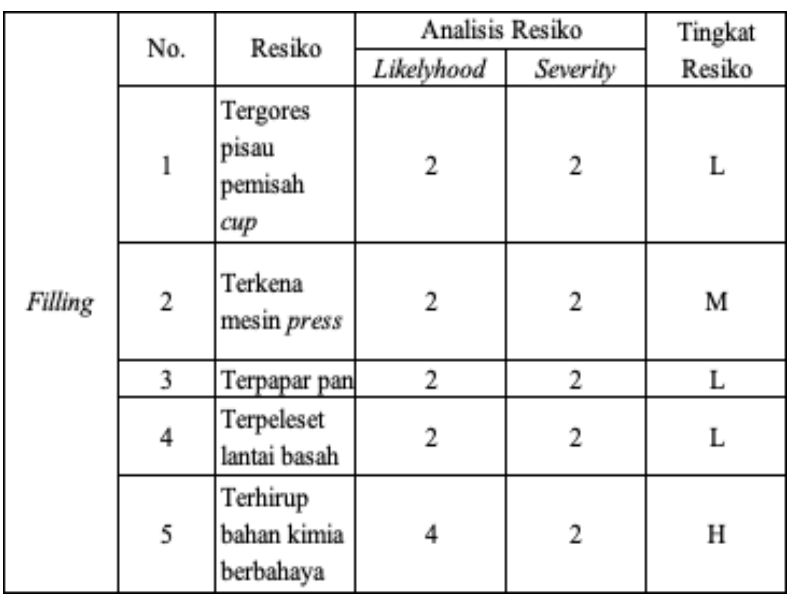

(Sumber: Pengolahan Data, 2018)
Tabel 11 Nilai Resiko Packing Pengendalian

\begin{tabular}{|c|c|c|c|c|c|}
\hline \multirow{5}{*}{ Packing } & \multirow{2}{*}{ No. } & \multirow{2}{*}{ Resiko } & \multicolumn{2}{|c|}{ Analisis Resiko } & Tingkat \\
\cline { 3 - 5 } & 1 & Terpapar pan & 2 & 2 & Likelyhood \\
\cline { 2 - 5 } & 2 & $\begin{array}{l}\text { Terpapar } \\
\text { percikan } \\
\text { panas dan } \\
\text { uap panas }\end{array}$ & 3 & 2 & Severity \\
\hline
\end{tabular}

(Sumber: Pengolahan Data, 2018)

\section{KESIMPULAN DAN SARAN}

Proses produksi teh skala industri terdiri dari beberapa tahap yaitu proses pengolahan teh (blending), pengisian pada cup (filling), dan pengepakan cup ke dalam karton (packing). Proses pengolahan teh memungkinkan adanya resiko kecelakaan yang terjadi pada para pekerja.

Bahaya dan resiko pengolahan teh pada proses pengolahan teh (blending) untuk bahayanya ada bahaya kimia dan fisik, dan untuk resikonya yaitu; ISPA dan terkena paparan panas. Untuk bagian pengisian pada cup (filling), bahaya nya adalah bahaya biologi dan kimia. Dan untuk resiko kesehatannya, yaitu paru-paru dan ISPA. Pengepakan cup ke dalam karton (packing) sendiri bahayanya yaitu; bahaya fisik sedangkan resikonya adalah terkena paparan panas.

Pengendalian bahaya dan resiko pengolahan teh pada proses pengolahan teh (blending), yaitu ; subtitusi, administratif, dan APD. Sedangkan pengisian pada cup (filling) pengendalian bahaya dan resikonya adalah engineering, administratif, dan APD. Dan untuk pengepakan cup ke karton (packing), pengendalian resikonya administratif dan APD.

\section{DAFTAR PUSTAKA}

British Standard Institute; 2007: OHSAS 18001: 2007.

Henrich, H. W., Petersen, D., \& Roose, N. (1980). Industrial accident prevention. 5thed., New York, McGraw.

HSE, U. (2002). COSHH Essentials-Easy Steps to Control Chemicals. London, HSE. http://www. coshhessentials. org. uk.

Mangkunegara, A. A. P. (2016). Manajemen sumber daya manusia perusahaan. PT.

Remaja Rosdakarya. 
Markkanen, P. K. (2004). Occupational safety and health in Indonesia= Keselamatan dan kesehatan kerja di Indonesia (No. 993679933402676). International Labour Organization.

Notoatmodjo, S. (2003). education and health Behavior. Rineka Cipta. Jakarta.

Rivai, Veithzal dan Ella Jauvani Sagala. 2010. Manajemen Sumber Daya Manusia Untuk Perusahaan Dari Teori Ke Praktek (Edisi Kedua). Jakarta: PT Raja Grafindo Persada.

Ramesh, R., Prabu, M., Magibalan, S., \& Senthilkumar, P. (2017). Hazard identification and risk assessment in automotive industry. International journal of ChemTech research, 10(4), 352-358.

Santoso, G. Manajemen keselamatan dan kesehatan kerja, 2004. Jakarta: Prestasi Pustaka. 
